\title{
Causality in macroeconometrics: some considerations about reductionism and realism
}

\author{
Alessio Moneta
}

\begin{abstract}
This paper investigates the varieties of reductionism and realism about causal relations in macroeconometrics. There are two issues, which are kept distinct in the analysis but which are interrelated in the development of econometrics. The first one is the question of the reducibility of causal relations to regularities, measured in statistics by correlations. The second one is the question of the reducibility of causes among macroeconomic aggregates to microeconomic behaviour. It is argued that there is a continuum of possible positions between realism and reductionism for both the questions, but, as far as the second question is concerned, the dominant position of mainstream macroeconometrics is strongly reductionist. The paper defends an integrative approach that emphasizes the gradual nature of many real world cases.
\end{abstract}

Keywords: causality, realism, reductionism, econometric models, identification problem

\section{INTRODUCTION}

A fundamental question in the philosophy of causation is whether causes are autonomous and observer-independent theoretical entities or they are reducible to non-causal facts like regularities. The latter choice corresponds to a reductionist approach, the former to a realist approach. Reductionist approaches to causality have been influential in philosophy of science since the time of Hume (see Hume 1739/40 and Hume 1748), and form the philosophical underpinning of probabilistic theories of causality (see, for example, Suppes 1970). Clive Granger's (1969) definition of causality can be interpreted as a paradigmatic application of the probabilistic theory to econometrics. On the other hand, there are realist approaches to causality, according to which causal relations have a reality autonomous from that of regularities. This idea bases the structuralist account of causality in econometrics of the Cowles Commission (see, for example, Haavelmo 1944, Simon 1953, Hurwicz 1962). In this account, the causal structure is derived by economic theory and formalized in a system of linear equations. Probability theory and statistical inference preserve an epistemological role. This is the role of measuring the strength of causal relations and testing the 
restrictions derived from the theory and imposed on the system of equations.

When one considers issues about causality in macroeconometrics, there is another important sense in which reductionism is involved. Indeed, a crucial question is whether causal relations among macroeconomic aggregates are reducible to more fundamental causal relations, namely relations among atomistic individual behaviours, or exist somewhat autonomously. This question has been rightly underlined by Hoover (2001), who links the issue of realism about causality in macroeconomics with a criticism of the programme of microfoundations for macroeconomics.

These two different forms of reductionism, which are much entwined in the development of econometrics, are separately scrutinized in this paper. The philosophical lexicon used is however the same. This permits to defend three claims. First, there is a continuum of possible positions between reductionism and realism. No sane position is at the extremes. Realism and reductionism are directions, and we show the macroeconometric approaches that go in one direction or in the other.

Second, we can find a continuum of econometric practices between reductionism and realism as regards the relationship between causes and regularities. But, as to the other relationship (macro-causes and microcauses), the dominant position is strongly reductionist.

Third, we defend an approach analogous to the 'integrative pluralism' proposed by Sandra Mitchell for biology (Mitchell 2003). The complexity of the subject studied by economics and the boundedness of our scientific representations suggest that there are many levels of reduction for macroeconomic causal relations - reductions both to statistical properties and to microbehaviors - which need to be considered on a case-by-case basis and to be integrated.

The rest of the paper is structured as follows. In the next section, we address the first question about reductionism: the relationship between causes and regularities. There is a large variety of philosophical positions between realism and reductionism. But the question regarded as central by the practitioners of macroeconometrics is not 'what are primary causes or probabilities?', but 'which relations remain stable?'. The third section is dedicated to this issue and to the related problem of identification. The fourth section addresses the problem of the relationship between causes among macroeconomic aggregates and micro-behaviour. The fourth section puts forward the main claims of the paper, presenting an integrative approach.

\section{CAUSES AND REGULARITIES}

The first issue of reductionism, that is relevant for the problem of causality in macroeconometrics, is the relationship between causes and regularities. The questions in this area are: which are primary - causal relations or 
regular conjunctions? Are causal relations nothing but regularities? Such questions concern the ontology of causality. ${ }^{1}$ Besides, there are epistemological questions about the relationship between causes and regularities: is it possible to have justified beliefs about causal relations starting from the experience of regularities? If the regular conjunction is a symmetric relation and causality is asymmetric, how do we infer the direction of causality? Is it possible to measure the strength of a causal relation via statistical methods?

A group of answers to these questions can be labelled as reductionist. Philosophers of science have scrutinized the varieties of reductionism ontological and epistemological - and have given a classification, according to the strength of reductionism (see Silberstein 2002). For example, saying that causal relations are nothing but regularities is tantamount to endorse an identity-based reductionism or eliminative reductionism (if one is willing to abandon causal claims). But there are weaker form of reductionism: one can say that the properties of causal relations are determined completely by the properties of regular conjunctions; this kind of reductionism would be called nomological supervenience or determination-based reductionism (Silberstein 2002: 84). Analogously, there is a classification of epistemological reductionism. In strong versions of it, causal claims can be entirely replaced by, or, more weakly, derived from statistical claims. In weak versions, causal claims may be reducible to statistical claims, but may have a pragmatic power, in terms of explanatory or predictive value, for example.

Realist and emergentist approaches are, roughly speaking, the converse of reductionism. Realism about causal relations is primarily an ontological claim: the reality of causal relations is autonomous from the reality of regular conjunctions. One has then to solve the epistemological problem of causal inference, and, for this scope, the use of statistical measures of regularities is not ruled out. Emergentist approaches claim that the properties of a whole or a complex 'emerge from' its parts, or, in other terms, 'go beyond the features of those parts' (Silberstein 2002: 90). This claim can be interpreted in an ontological sense, when with properties we mean objective relations between real items, independent of any epistemic consideration. But it can also be interpreted in an epistemological sense, when with properties we mean relations that depend upon 'our abilities to comprehend the nature of the links or dependencies among real world items' (Silberstein 2002: 90).

These philosophical approaches about the relationship between causes and regularities form the substratum of the definitions of causality and the methods of causal inference that we find in macroeconometrics. Our claim is that more than definite positions classifiable as realist or reductionist, we find in macroeconometrics a continuum of visions about causality. Some of them go in the realist direction, some of them in the reductionist direction. Besides, if we take into consideration the historical development of econometrics, we record an evolution of positions about causality. 
As Hoover (1998) points out, two approaches are commonly found in empirical economics, which he calls the probabilistic approach and the structuralist approach. The probabilistic approach has its philosophical roots in Hume. According to the traditional interpretation of Hume (pace Strawson 1989), causal relations are ontologically reducible to noncausal relations. Causes are not directly observable, but can be inferred by the experience of 'constant conjunctions'. In An Enquiry Concerning Human Understanding (1748), Hume gives a twofold definition of causality: 'we may define a cause to be an object, followed by another, and where all the objects, similar to the first, are followed by objects similar to the second. Or in other words where, if the first object had not been, the second never had existed' (Hume 1748: sect. VII, part II). The probabilistic theory of causality is based, roughly speaking, on an elaboration of Hume's first definition. This theory was proposed principally by Suppes (1970). The direct predecessors are Reichenbach (1956) and Good (1961-62); further developments are in Eells (1991). The first definition of causality given by Suppes is the following: an event $A$ causes prima facie an other event $B$ if and only if: (a) $A$ and $B$ occur, and $A$ occurs before $B ;(b) P(B \mid A)>P(B)$ (Suppes 1970: 12). The basic idea is that a cause must somewhat make its effect more likely. It is an elaboration of Hume's definition because it reduces the nature of causes to probability distributions (instead of simple regularities), which are directly measurable. As in Hume, the definition contains in itself the procedure of inference.

Clive Granger's account of causality, which is maybe the most influential procedure of causal inference in econometrics, is based upon such a probabilistic theory of causality (see Spohn 1984). Granger defines causality in the following way. A variable $A$ causes a variable $B$ if the probability of $B$ conditioned on its own past history and the past history of $A$ (besides the set $\Omega$ of the available information) does not equal the probability of $B$ conditional on its own past history alone (and $\Omega$ ) (Granger 1980).

The structuralist approach that we find in macroeconometrics goes more into the direction of realism. It assumes the existence of economic structures that are autonomous and primary with respect to regularities. Probability relations do not enter in the ontology of causality, but enter in the epistemology of causality, according to this approach. The Cowles Commission method of economic modelling is based upon this approach. Economic theory dictates the structure existing among macroeconomic variables and the role of probability theory and statistics is that of measuring the strength of causal relations, and that of testing the theoretical restrictions.

Although the probabilistic and the structuralist approach go in opposite directions - reductionist vs. realism - there is a continuum of positions. This is because the fundamental question faced by the practitioners of macroeconometrics is not 'which relations - causes or regularities - are 
real?', but 'which relations are stable?'. With stable or autonomous relations, one generally means relations that are invariant to interventions among parameters. In a stable relation between $A$ and $B$, one can manipulate $A$ and have a predictable outcome on $B$. That fits very well with one of the declared goals of macroeconomics: that of suggesting policy interventions. In the next section, we show how the concept of stable relation is connected with that of causality and how these two concepts have been evolving.

\section{STABLE RELATIONS ${ }^{2}$}

\subsection{The problem of identification}

The thesis that the various econometric approaches to causality form a continuum of positions between realism and reductionism is demonstrated by the debate about autonomous or stable relations. The question as to which relations are to be considered stable and may be used for policy evaluation is strictly connected in econometrics with the problem of identification. In an article of 1979, which has the title After Keynesian Macroeconomics, Robert Lucas and Thomas Sargent write: 'The problem of identifying a structural model from a collection of economic time series is one that must be solved by anyone who claims the ability to give quantitative economic advice' (Lucas and Sargent 1979: 298-99). Indeed, the Lucas critique is directed to an approach to the problem of identification, which Lucas and Sargent call Keynesian macroeconometrics, and it is a proposal of an alternative method to address this problem.

Suppose $\mathrm{X}_{\mathrm{t}}$ is a $k \times 1$ vector of macroeconomic time series, which is assumed to be non-stationary. The Wold representation is:

$$
\Delta \mathrm{X}_{\mathrm{t}}=\mu+\mathrm{C}(\mathrm{L}) \epsilon_{\mathrm{t}},
$$

where $\epsilon_{\mathrm{t}}$ is a white noise vector, which is serially uncorrelated with a mean of zero and variance-covariance matrix $\Sigma_{\epsilon}, \mathrm{C}(\mathrm{L})$ is a lag polynomial (so that $\mathrm{C}$ (L) $\epsilon_{\mathrm{t}}=\epsilon_{\mathrm{t}}+\mathrm{C}_{1} \epsilon_{\mathrm{t}-1}+\mathrm{C}_{2} \epsilon_{\mathrm{t}-2}+\ldots$ ), and $\mu$ is a constant term. ${ }^{3}$

Of course, there are infinite representations of this form, since it is sufficient to define a lag polynomial $\mathrm{A}(\mathrm{L})=\mathrm{C}(\mathrm{L}) \mathrm{A}_{0}$ for an appropriate matrix $A_{0}$ such that the vector $u_{t}=\left(A_{0}\right)^{-1} \epsilon_{t}$ is still a white noise. What economists are looking for, however, is a model that represents stable relations and in which white noise terms are interpretable as economic shocks. Such a model is called a structural model and has the form:

$$
\Delta \mathrm{X}_{\mathrm{t}}=\mu+\Gamma(\mathrm{L}) \eta_{\mathrm{t}},
$$

while the corresponding reduced form model is of the form (1) with $\epsilon_{t}=\Gamma_{0} \eta_{t}$ and $\mathrm{C}(\mathrm{L})=\Gamma(\mathrm{L})\left(\Gamma_{0}\right)^{-1}$.

The solution to the identification problem consists in finding a way to deduce $\eta_{\mathrm{t}}$ and $\Gamma(\mathrm{L})$ in (2) from $\epsilon_{\mathrm{t}}$ and $\mathrm{C}(\mathrm{L})$ in (1). 


\subsection{Cowles commission approach}

In Keynesian macroeconometrics - which is the approach to econometrics criticized both by Lucas and Sargent and, as we will show later, by Christopher Sims - structural parameters are identified by the imposition of several types of a priori restrictions, for example by classifying variables as exogenous and endogenous. In the form of equation(2) this would correspond to assuming that certain blocks of $\Gamma_{0}$ are zero, as illustrated in King et al. (1991).

Hoover notes that 'there is a certain irony in criticizing any econometrics as Keynesian, given Keynes's own scepticism of econometrics. ... What is of course true is that most builders of large-scale macroeconometric models classified themselves as Keynesian' (1988: 270). Keynes's scepticism about the first developments of econometrics (see Keynes 1939) can be interpreted as a consequence of his own view of economic causal structures. Keynes points out that to measure economic relationships with statistical techniques alone we would need beforehand a correct and complete list of the significant causes, which seems to be a too demanding request to economic theory (Keynes 1939: 560). Lawson (1989) claims that we can reconstruct from Keynes's writings a view of economic processes as constituting a nonatomistic and open system (p. 247). What is certainly true is that Keynes is very sceptical about the capacity of statistical techniques of being able to measure a cause-effect relationship, because the mechanism that produces such relationship is intertwined with other mechanisms (see, for example, Keynes 1939: 560). However, Keynes believes that causal mechanisms do exist in the economy and that knowledge of them is also possible, but we do not obtain it from empirical regularities. In philosophical terms, Keynes's view of causality is strongly non-reductionist and realist: causal facts are primary with respect to non-causal facts, such as empirical regularities. Moreover, starting from the measuring such regularities we are not able to get knowledge of causes, not even with the help of economic theory.

The Cowles Commission programme in econometrics aimed to give a formal and quantitative treatment of the macroeconomic theories that had been developed in the 1930s. The focus was Keynesian theory, but interpreted as a general equilibrium system, and without endorsing Keynes's approach to probability and statistics. In The Probability Approach to Econometrics (1944), Haavelmo proposes the following tenets:

(i) the economy as a whole may be characterized as a system of relations of mutual-dependence type (where 'everything depends upon everything else'), but built up from systems of relations of cause-effect type, which represents the various sectors of the economy (Haavelmo 1944: 22);

(ii) it is possible to identify the structural parameters of these relations from 'a theoretical relation, a design of experiments and a set of 
observations' (Haavelmo 1944: 14). The experiments are those which 'Nature is steadily turning out from her own enormous laboratory, and which we merely watch as passive observers' (Haavelmo 1944: 14);

(iii) these relations are essentially stochastic (Haavelmo 1944: 40).

Haavelmo is confident about the possibility of isolating autonomous relations. To explain what is an autonomous relation, Haavelmo uses a mechanical analogy:

If we should make a series of speed tests with an automobile, driving on a flat, dry road, we might be able to establish a very accurate functional relationship between the pressure on the gas throttle (or the distance of the gas pedal from the bottom of the car) and the corresponding maximum speed of the car. And the knowledge of this relationship might be sufficient to operate the car at a prescribed speed. But if a man did not know anything about automobiles, and he wanted to understand how they work we should not advice him to spend time and effort in measuring a relationship like that. Why? Because (1) such a relation leaves the whole inner mechanism of a car in a complete mystery, and (2) such a relation might break down at any time, as soon as there is some disorder or change in any working part of the car. ... We say that such a relation has very little autonomy, because its existence depends upon the simultaneous fulfillment of a great many other relations, some of which are of transitory nature.

(Haavelmo 1944: 27-8)

Thus, what distinguishes autonomous relations from empirical regularities is, on the one hand, the explanatory power, on the other hand the invariance under new conditions. Haavelmo does not use the word causal in the quoted passage (he uses more causal notions to refer to microbehaviours), but other exponents of the Cowles Commission (see e.g. Simon 1953 and Hurwicz 1962) use the related concept of 'invariance under intervention' to define those special causal relationships that constitute the structural equations in an econometric model.

According to Haavelmo, 'there are more fundamental relations than those that appear before us when we merely stand and look' (1944: 38). These relations are among aggregates, but they are underpinned by 'fundamental behaviouristic relations' that describe 'individuals' decisions to produce and to consume' (1944: 28). The fundamental relations are causal, according to Haavelmo, in the sense that individuals take the best decisions given the conditions in which they are involved. But Haavelmo claims that we are able to discover autonomous relations among aggregates, not reducible to constant relations. What distinguishes autonomy from constancy or persistence of a relation is that autonomy 'refers to a class of hypothetical 
variations in the structure, for which the relation would be invariant, while its actual persistence depends upon what variations actually occur' (1944: 29).

The definition of causality as structural relations invariant to intervention given by Simon is analogous to Haavelmo's notion of autonomy. The focus of Simon (1953) is on the syntactic properties of the model. The main issue is to determine what are the algebraic properties that a model should satisfy in order to determine its causal ordering. However, Simon's (1953) discussion of observational equivalent systems of equation and his definition of structural equations as those equations representing causal relations invariant with respect to interventions suggest that the ultimate interest is mapping to causal relations that exist somewhat autonomously in the world.

How can these relations be tested and measured? The tools are given by the well-known simultaneous equation models (SEM). In this approach, it is assumed that there exists an underlying mechanism that generated the data. It is emphasized, however, that without a priori restrictions imposed by economic theory it would be almost impossible to identify (causal) economic relationships.

In its declared objectives, the Cowles Commission methodology is nonreductionist and realist. There is something in the reality at the macro-level that distinguishes autonomous (Haavelmo) or causal (Simon) relationships from empirical regularities. Haavelmo explains the causal relationships as underpinned by causal microbehaviours, while Simon is more focused on causality as a property of a model, but both authors believe in the possibility of measuring causal properties of objective economic processes.

In the practice of econometrics, however, empirical studies inspired by the Cowles Commission methodology often have failed to endorse a realist approach. Especially in the 1970s, when doubts were increasing about the reliability of Keynesian macroeconomic theory, econometricians were using theoretical restrictions, without much believing on the real existence of causal relations associated with such restrictions (for a criticism of this practice, see Sims 1980). Lawson (1989) claims that Haavelmo's approach is ultimately instrumentalist. He states that Haavelmo's concern about autonomous relation denotes a realist orientation, but which is counterposed to a view of an econometric model as 'serving merely as an instrument or tool for deriving practical statements'. This is not enough, however, for an instrumentalist position, as defined in philosophy of science: a realist position does not exclude that models are instruments for deriving practical statements. The instrumentalist position, on the other hand, typically excludes that we find the goal of true representation of the reality among the goals that a theory or a model is pursuing (Mäki 1998). Since the goal of representing the 'real structure' of the economy (Haavelmo 1944: 28) is certainly present in the Haavelmo's approach, the label of instrumentalist is hardly applicable. 
However, when we consider the applications of the Cowles Commission methodology, it becomes problematic to prove, in a non-experimental setting such as economics, that some relations are invariant under interventions. In order to achieve identification of large-scale econometric models, typically used until the end of 1970s, a large class of a priori restrictions, which were dictated not only by economic theory, but also by common practices not grounded on representations of the reality, were used. Thus, in the econometrics inspired by the Cowles Commission, we find a continuum of positions between realism and reductionism, and between realism and instrumentalism. The most realist-oriented positions are found in the theorizers of the Cowles Commission approach, the most instrumentalist and reductionist-oriented positions are found in the practitioners of the 1970s, inspired by such approach, which treat regular relations as if they were generated by causal structures, and models as useful instruments of predictions, without much believing in their power of representing true causal relations of the world.

\subsection{Lucas critique}

Lucas points out that the restrictions imposed by the Keynesian approach to macroeconometrics are not sound, because the parameters estimated are not invariant to change of policy regime. Stable relations should be estimated from the underlying choices of individual agents, according to Lucas. On the other hand, Keynesian macroeconomics has neglected two 'classic' postulates: agents act in their own interest and markets clear.

The seminal paper of Lucas (1976) can be interpreted as a criticism of the solution given to the identification problem by the Cowles approach, and of the use of large-scale macroeconometric models based on this approach. Lucas considers an analogous problem of autonomy or invariance.

His own important contribution [to the problem of invariance] is to observe that one of the relations frequently omitted from putative causal representations is that of the formation of expectations. He notes, further, that the formation of expectations may depend upon people's understanding of the causal structure in general and of the process of policy formation in particular.

(Hoover 1988: 191-2)

Macroeconometric models embody unstable relationships between aggregate data, according to Lucas, as long as they do not represent the optimization problems of agents in general equilibrium with rational expectations. Hansen and Sargent (1980) propose a method to solve the problem of identification, which is immune to Lucas critique. In the form of equation (2), it would correspond to impose cross-equation restrictions on the various elements of $\Gamma(\mathrm{L})$. The peculiarity of these restrictions is that they are grounded in the bedrock of given tastes and technology. 
Thus, the properties of an economic aggregate are to be explained, according to Lucas, by reference to the behaviour of rational economic agents such as postulated by neoclassical microeconomics. Moreover, Lucas and his fellows recommend the use of representative agent models, in which the behaviour of diverse agents is in turn reduced to choices of one 'representative' standard utility maximizing.

Stability of economic relations is confined within the microbehaviours, in the Lucas's approach. All the economic relations are to be founded on individual decision-making processes, which take into account that individual agents do their best given the available information. The rational behaviour of economic agents is not coupled by relations that can be used for economic policy control. One can argue that controllability is something different and perhaps stronger than causality, by considering examples of causal relations that vanish once the cause is used for control (Granger 1980). Indeed, the rational expectation hypothesis, while at the micro-level it requires a notion of causal structure consistent with the notion used by the Cowles Commission, involves the notion of Granger-causality, when it considers aggregate macroeconomic variables. The concept of Grangercausality is much weaker than controllability. A definition of Grangercausality equivalent to the one given in section 2 is the following: a time series $\left\{x_{t}\right\}$ (Granger) causes the time series $\left\{y_{t}\right\}$ if the knowledge of the past and present values of $\left\{x_{t}\right\}$ contributes to forecasting $\left\{y_{t}\right\}$, as it reduces the variance of the prediction errors.

Granger-causality plays a 'natural role' in these models, because

agents' decision rules typically involve predictions of future values of the stochastic processes, say $w_{t}$, that they care about but cannot control, e.g., in competitive models output prices and/or input prices. ... All processes [which regard aggregate macroeconomic variables] agents see and that Granger cause $w_{t}$ belong in agents' decision rules.

(Hansen and Sargent 1980: 92)

In philosophical terms, Lucas's approach is reductionist, in the sense that macroeconomic causal relations are reduced to micro-behaviours in which predictability of macroeconomic variables plays a primary role. However, Lucas claims that we are able to distinguish between objective microeconomic structures and empirical regularities. Thus, at the micro-level Lucas maintains a realist position.

\subsection{VAR approach}

Sims (1980) pursues the criticism of traditional macroeconomic models further. He claims that 'econometricians imposed large numbers of restrictions that were incredible in the sense that they did not arise from 
sound economic theory or institutional or factual knowledge, but simply from the need of the econometrician to have enough restrictions to secure identification' (Hoover 1995: 6). But the reaction is alternative to the rational-expectations econometrics approach. While one stream of econometric research after the Lucas critique continued to pursue identification of structural models, by using restrictions grounded in individual decisionmaking, Sims argues that economic relations are in principle not identifiable: 'Sims proposed that macroeconometrics give up the impossible task of seeking identification of structural models and instead ask only what could be learned from macroeconomic data without imposing restrictions' (Hoover 1995: 6).

The approach proposed by Sims deals with unrestricted reduced form equations, namely Vector Autoregressive (VAR) models. Each variable is considered as endogenous and it is regressed on lagged values of itself and of all the other variables. Sims (1982) argues that his programme is immune to the Lucas critique, because policy action consists in an 'implementation of a fixed or slowly changing rule' and so the agents form probability distributions over the range of possible policy stances. The shocks embody all the surprises and innovations to the information set of economic agents.

More generally, in VAR models, the shocks represent exogenous actions on the economy. These actions are usually given a causal interpretation, although they cannot be systematically exploited by the policymakers. A large part of the literature about VAR models has been dedicated to transforming the random terms, in order to get uncorrelated exogenous shocks, which can be given an economic interpretation. In terms of equation(2), Sims (1980) assumes that the covariance matrix $\Sigma_{\eta}$ of the structural shocks $\eta_{\mathrm{t}}$ is diagonal and that $\Gamma_{0}$ is triangular. The form of $\Gamma_{0}$ reflects the causal structure among the contemporaneous variables: if $\Gamma_{0}$ is triangular we have a Wold causal chain, in which each variable causes all the variable below in the vector and each variable does not cause any variable above in the vector. ${ }^{4}$ Since the orthogonalizing transformations form an observationally equivalent class, the so-called Structural VAR approach proposes to use for the identification restrictions derived from a priori knowledge or economic theory (see, for example, Bernanke 1986). Thus, Structural VAR models recover some issues of the Cowles-Haavelmo approach. In fact, VAR models end up to be very widely used by very different econometric and economic schools.

In the Sims's approach, macroeconomic relations are not stable under intervention, since they cannot be exploited by policymakers (as in Lucas). Is there something in the relations between shocks and variables, which has a causal attribute or at least distinguishes such relations from empirical regularities? Theoretically yes, but the true economic shocks are not identifiable from data alone and using much a priori restrictions would be to repeat the flaws of large-scale macroeconomic models, according to Sims. 
Therefore, VAR models are often used more for their predictive power, than as an explanation of causal relations (see Stock and Watson 2001). Structural analysis is limited to measure the effects of the shocks calculating impulse response functions, which are the partial derivatives of each variable with respect to each shock. But, since the impulse response function depends on the way the structural shocks have been derived from the reduced form, the problem of identification reappears.

In the context of VAR models it is rather straightforward to set tests of Granger-causality, which has been mentioned for the rational expectations models. But Granger-causality is more a measure of incremental predictability than of causality, as it has been pointed out by several works (see, for example, Leamer 1985, Hoover 2001).

In philosophical terms, the VAR programme proposed by Sims (1980) is more oriented towards an instrumentalist and reductionist position. It tends to instrumentalism, because the identification of real causal structures is not pursued. The main focus is prediction or the collecting of stylized facts to be confronted with theories, but without believing that econometric tools capture a structure not reducible to statistical regularities. ${ }^{5}$ It tends to reductionism, in the sense that causal relations are reduced to non-causal facts (statistical properties).

However, the developments of Structural VAR (Bernanke 1986, Blanchard and Watson 1986, Sims 1986), to which Sims himself contributes, are an attempt to give a more realist flavour to the study of the structural shocks and the impulse response functions: the goal is to find reliable $a$ priori restrictions about the contemporaneous structure of the variables, that permit an economically meaningful interpretation of economic shocks. Recent works on Structural VAR (see, for example, Swanson and Granger 1997, Awokuse and Bessler 2003, Demiralp and Hoover 2003, Moneta 2003) also have a more realist orientation. They try to articulate the actual contemporaneous causal structure of the macroeconomic variable, starting from the study of the partial correlations among estimated VAR residuals. But this can be done only assuming a priori that a contemporaneous causal structure is invariant in a certain time window.

\section{MACRO-CAUSES AND MICRO-CAUSES}

As the issues raised by the Lucas Critique show, there is another question about causality, which is intertwined with the question about the relationship between causes and regularities, but which we should keep conceptually distinct. This is the question about the relationship between causes among macroeconomic variables and causes among microeconomic variables, which we shall call the relationship between macro- and microcauses. This question is intertwined with the question about the relationship between causes and regularities, because the relationship 
between macro- and micro-causes could be a relationship via regularities among macroeconomic variables and regularities among microeconomic variables. However, it should be kept distinct, because one can have different positions about the relationship between macro- and micro-level both in the reductionist and in the realist approach to causes/regularities. In other words, one can be realist about the relationship between causes and regularities, but can claim that macro-causes are entirely reducible to micro-causes, and one can be reductionist about the relationship between causes and regularities, but can claim that regularities among macroeconomic aggregates are autonomous from regularities among microeconomic variables.

To analyse the relationship between macro- and micro-causes, we can use the same philosophical language we have used to interpret the varieties of relationships between causes and regularities. Analogously to the questions posed at the beginning of section 2, there is a first group of questions that are ontological: do macro-causes exist independently of micro-causes, or are completely determined by micro-causes? Are macro-causes nothing but micro-causes? Here the ontology of the relation is very much connected with the ontology of the relata. In other words, these questions are very connected with questions about the reducibility of macroeconomic variables to microeconomic variables. A second group of questions are epistemological: can we theorize about and model macro-causes directly, or do we need to derive all aggregate behavioural specifications from atomistic individual behaviour?

Again, we may have varieties of ontological and epistemological reductionism. If one claims that macro-causes do not actually exist, and that they are just micro-causes, one defends an identity or eliminative (if one is willing to abandon claims about macro-causes) reductionism. There are weaker forms of ontological reductionism: one can say that macro-causes are completely determined by micro-causes and/or that macro-causes are supervenient upon micro-causes. What this means is that if two possible worlds $W$ and $W^{*}$ agree with respect to the micro-causes, they must also agree with respect to the macro-causes (see Tooley 1993: 173).

We may also have varieties of epistemological reductionism. One can argue that macro-causal claims have to be replaced by micro-causal claims, that macro-causal claims are to be derived from micro-causal claims, or that macro-causal claims are in principle derivable from micro-causal claims but the former maintain a pragmatic power.

Analogously to what we said in section 2, we may have realist and emergentist positions, which are the converse of reductionist positions. Emergentist positions about the relationship between macro- and microcauses claim that the properties of macro-causes go beyond the properties of micro-causes. Again, this statement can be interpreted in an ontological or an epistemological sense. 
Our point here is that we have a continuum of philosophical positions between reductionism and emergentism about the relationship between macro- and micro-causes, but in the practice of macroeconometrics we find as dominant paradigm the extremely reductionist position of Lucas. The programme of microfoundations established by Lucas aims to reduce macroeconomics to microeconomics so that 'the term 'macroeconomic' will simply disappear from use and the modifier 'micro' will become superfluous' (Lucas 1987: 107). The macroeconometric models after the Lucas critique are prevalently built upon the idea that the sources of causal relations among macroeconomic variables are in the decisions of individual agents. In fact, it is very reasonable to conceive macroeconomic variables as the outcome of the interaction of large numbers of decisions and behaviours made by agents and institutions. The problem is that in the class of models promoted by Lucas and his fellows - representative agent models - all the activities pursued by individuals are modelled 'as the choice of one 'representative' standard utility maximizing individual whose choices coincide with the aggregate choices of the heterogenous individuals' (Kirman 1992: 117).

The identity-based and, for many respects, eliminative reductionism pursued by Lucas has exerted a great influence on macroeconometric models building, but it has also been strongly criticized. Hoover (2001), for example, defends the thesis that macroeconomic aggregates supervene upon microeconomic reality.

What this means is that ... if two parallels worlds possessed exactly the same configurations of microeconomic or individual economic elements, they would also possess exactly the same configurations of macroeconomic elements. It is not the case, however, that the same configuration of macroeconomic elements implies the same configuration of microeconomic elements.

(Hoover 2001: 120)

Supervenience, can be interpreted, as mentioned above in this section, as a weak version of reductionism, alternative to the stronger version of eliminative or identity-based reductionism. Hoover's argument in defence of supervenience is instrumental to establish that macroeconomics is suitable subject for a realist causal account and that, as a consequence, 'the central rationales for the programme of microfoundations for macroeconomics' can be eliminated (Hoover 2001: 109).

The representative-agent models have been strongly criticized by Kirman (1992). His main argument is that '[t]here is simply no direct relation between individual and collective behavior'. Indeed, 'there is no plausible formal justification for the assumption that the aggregate of individuals, even maximizers, acts itself like an individual maximizer'. Moreover, 'the sum of the behavior of simple economically plausible individuals may 
generate complicated dynamics' (Kirman 1992: 118). What Kirman seems to suggest is a more sophisticated form of derivative reductionism: macrocauses may be derivable from microeconomic behaviours but the compositional principle may be non-additive or non-linear.

There are other criticisms more directed against methodological individualism, to which the programme of microfoundations aspires. However, methodological individualism is a broader principle than the Lucas's programme of microfoundations. According to methodological individualism, 'explanations of social, political, or economic phenomena can only be regarded as adequate if they run in terms of the beliefs, attitudes, and decisions of individuals' (Blaug 1992: 44). In this context, the question that arises is: is it possible to conceive causal relations among macroeconomic aggregates that are under-determined by microeconomic decisions? In other words, could there be relations among aggregates with some degrees of invariance with respect to microeconomic decisions?

For example, Martel (1996: 141) claims that it is methodologically acceptable to theorize about and model aggregate behavior directly, without requiring all behavioral specifications to be derived from atomistic individual behaviors'. This statement can be interpreted as a form of epistemological emergentism.

On the other hand, it would be possible to defend ontological emergentism about the relationship between macro- and micro-causes. There have been some efforts to define an emergent property in economics. For example Hodgson (1998: 157) defines an emergent property as a feature of a complex system that

(i) can in principle be described in terms of entities at the macro-level, without references to the attributes of the micro-level;

(ii) persists longer than the underlying micro-interactions;

(iii) is not explicable entirely in terms of properties of elements at the micro-level (see also Lane 1993: 91).

\section{AN INTEGRATIVE APPROACH}

This investigation about the varieties of reductionism and realism, as regards the specific problems of the relationship between causes and regularities, and of the relationship between causes among macroeconomic aggregates and microeconomic behaviours, suggests three points, which are the main claims of this paper.

First, there is a continuum of possible positions between reductionism and realism (see, for example, Silberstein 2002: 99). Generally speaking, realism (or emergentism) and reductionism are directions, and not positions. No sane position is at the extremes. This is particularly clear for the case of the relationship between causes and regularities, and of the relationship 
between macro- and micro-causes. For example, the position that causes among economic variables exist completely autonomously from regularities - let alone mind-independency - does not fit with the standard interpretation of causal claims in economics. Economists, especially macroeconomists, are interested on those causes that are connected with a regular behaviour of economic variables. That is probably due to epistemological reasons, since we are able to measure causes as long as they repeatedly produce their effects, or, at least, it is simpler to measure causes connected with regular behaviours. There may also be pragmatic reasons: causes that are connected to regular observations are exploitable and thus useful - in economic terms for economic agents. The interest on causes expressing regularities may be, of course, completely consistent with the non-reductionist claim that causes are primary with respect to regularities. The non-reductionist position, however, cannot be taken to extremes of complete independence: causes relevant to economics are strictly connected to regularities and drawing the borderline between causes and regularities (or deciding what is primary) is not always an easy task.

On the other hand, the position that causal relations are completely reducible to non-causal states of affairs does not fit with the standard interpretation of causal claims in economics either. When we speak about causes in economics, we would like to have something more than constant conjunctions, say correlations. First of all, we would like to have a relation that is asymmetric, and not symmetric like correlation. This is connected with the issue of control mentioned before: a correlation can be hardly exploited for policy intervention. Moreover, the actual existence of theoretical entities like causes or structures (as opposed to empirical regularities) seems to be the base of success and explanatory power of science. In a nutshell, causes without regularities seems a too strong claim, regularities without causes a too weak claim.

Analogous considerations can be formulated as regards to the relationship between macro- and micro-causes. A strong emergentist position about macro-causes is hard to defend. Indeed, such a position would imply that the properties of macroeconomic aggregates are ontologically independent of microbehaviours, and that the former are not derivable from the latter. But that would leave macro-causes themselves in a mystery. On the other hand, a strong reductionist position as regards macro- to micro-causes neglects the complexity of aggregation, as illustrated in section 4 .

In the development of econometrics, as far as the relationship between causes and regularities is concerned, we find a continuum of positions. We have also find an historical tendency: from positions that go in the realist direction with the Cowles Commission approach, to positions that go in the reductionist direction with the VAR approach.

The second point we want to make is that, while we find in the development of econometrics a continuum of positions between realism and 
reductionism, as to the relationship between causes and probabilities, in mainstream empirical macroeconomics, we do not find a continuum of positions between emergentism and reductionism, as far as the relationship between macro-causes and micro-causes is concerned. Indeed, the majority of macroeconometric models is built upon the tenets of Lucas's programme of microfoundations, which represents a strong type of reductionism, as argued in section 4 .

Third, our investigation suggests that causal relations play a strong pragmatic role in scientific knowledge. There is no unique definition of causes and no unique reduction of macro-causes to microbehaviours.

The relationship between causes and regularities depends strongly upon our belief of existence of theoretical laws (if there is), or upon our belief as to what remains stable in the processes under investigation. Recent developments of procedures to draw causal inferences from statistical data have clarified the complex relations between causes and correlations (Spirtes et al. 2000, Pearl 2000). The idea is to use the rigorous language of graphical models to represent causal structures. The procedure of causal inference is based upon two assumptions. The first - the Causal Markov Condition - says (translated from the technical language of graphical models) that, given a group of variables $V=\left\{X_{1}, \ldots, X_{\mathrm{n}}\right\}$ and a probability distribution over $V$, for every variable $X_{i}$ in $V$ it holds that, conditional on its direct causes, $X_{i}$ is independent of every other variable in $V$ except its effects. ${ }^{6}$ The second - the Faithfulness Condition - says that every conditional independence relationship true in the probability distribution is also implied by the Causal Markov Condition. As Pearl (2000) points out the Faithfulness condition is equivalent to a condition about stability. Indeed, the Faithfulness condition says that every conditional independence relation is generated by the causal structure, and that those dependencies that are not stable vanish when the parameters are slightly modified.

It is important to notice that such conditions set the boundary of the derivability of causal relations from correlations. For example, there are environments where we should expect these conditions to be violated. The Causal Markov condition does not hold if relevant variables to the causal structure are not included in $V$, if probabilistic dependencies are drawn from non-homogenous populations, if variables are not properly distinct from one another or if we are in environments (for example in quantum mechanical experiments) where causality cannot assumed to be local in time and space. However, in all the environments where we can exclude 'nonsense correlations' and assume temporal and spatially local causality, we can assume the Causal Markov condition to be satisfied. Moreover, if we can assume a satisfactorily degree of stability, we can also assume Faithfulness. This suggests, again, that there is a continuum of possible situations about the relationship between causes and regularities. 
Regarding the relationship between causes among macroeconomic aggregates and microbehaviour, what the investigation suggests is that there may be causal relations at different levels of the scientific (economic) discourse and among different levels. What we are trying to defend here is a form of 'integrative pluralism', analogous to what defended by Sandra Mitchell (2003) for biology. Mitchell argues that the complexity of the subject studied by biology and the various sciences 'and the limitations of our representations of acquired knowledge jointly entail an integrative, pluralistic model of science' (2003: 2). This consideration can be easily extended to economics. We have different levels of aggregation and we can find 'intra-ordinal' causal relations, which connect properties of the aggregates of the same order, and 'trans-ordinal' causal relations, which connect properties of different orders. There is no level that is causally sufficient for the other levels, even if the entities from which all aggregates are built are ultimately one kind, which is individual human beings. The rejection of the strong varieties of reductionism, however, should not lead us endorse 'anything goes' pluralism, usually associated with Paul Feyerabend's epistemological anarchism (Feyerabend 1975). Mitchell argues that there is a middle ground between 'the advocacy of retaining all, possibly inconsistent, theories that emerge from a community of investigators' and 'the insistence that any collection of analyses of the same phenomena must be reduced to a single theory' (Mitchell 2003: 186). The integrative pluralism defended by Mitchell is alternative also to an isolationist approach, that defends a vision of scientific enterprise as founded on multiple levels of analysis, but neglects questions about the relations among the different levels of analysis.

We have defended a similar pluralist ontology about causes in macroeconometrics. That means that any approach to the two relationships considered (causes vs. regularities and macro-causes vs. micro-causes) should emphasize the gradual and fragmentary nature of many real world cases, and that richer scientific explanations can be obtained, if the different levels of causes are integrated.

Alessio Moneta

Sant'Anna School of Advanced Studies, Pisa amoneta@sssup.it

\section{NOTES}

1 There are also important ontological questions as to what sort of things the relata of causality exactly are - whether they are events, facts, states of affairs, propositions, etc. - and questions about the relationship between the relata of causality and the relata of regularities, but we do not face this issue here, and we assume that the relata are just macroeconomic variables, without going more deeply into this issue; something more about this will be said in section 4 . 
2 This section is built upon Moneta (2004: section 1.3).

3 The illustration of the identification problem in this terms and notation follows King et al. (1991: 822).

4 In that case, $\Gamma_{0}$ can be easily obtained via the Choleski factorization of the covariance matrix of the estimated residuals $\Sigma_{\epsilon}$.

5 In fact there is a somewhat circular reasoning in some Structural VAR econometric practices, as argued by Uhlig (1999): to obtain such stylized facts several alternative theoretical restrictions are used and the criterion of choice among them turns out often to be the conforming of the empirical results to the accepted background theoretical knowledge.

6 The Causal Markov Condition can also be seen as a graphical interpretation of the principle of the common cause, formulated by Reichenbach (1956). The principle of common cause says that if $X_{i}$ and $X_{j}$ are probabilistically dependent, then either $X_{i}$ causes $X_{j}$, or $X_{j}$ causes $X_{i}$, or $X_{i}$ and $X_{j}$ are effects of some common cause $X_{h}$.

\section{REFERENCES}

Awokuse, T.O. and Bessler, D.A. (2003) 'Vector autoregressions, policy analysis, and directed acyclic graphs: an application to the US economy', Journal of Applied Economics 6: 1-24.

Bernanke, B.S. (1986) 'Alternative explanations of the money-income correlation', in K. Brunner and A.H. Meltzer (eds) Real Business Cycles, Real Exchange Rates, and Actual Policies, Carnegie-Rochester Conference Series on Public Policy, vol. 25, Amsterdam: North-Holland, pp. 49-100.

Blanchard, O. and Watson, M. (1986) 'Are all business cycles alike?', in R.J. Gordon (ed.) The American Business Cycle, Chicago: University of Chicago Press, pp. 123-60.

Blaug, M. (1992) The Methodology of Economics: or How Economists Explain, Cambridge: Cambridge University Press.

Demiralp, S. and Hoover, K.D. (2003) 'Searching for the causal structure of a vector autoregression', Oxford Bulletin of Economics and Statistics 65: 745-67.

Eells, E. (1991) Probabilistic Causality, Cambridge: Cambridge University Press.

Feyerabend, P.K. (1975) Against Method, London: New Left Books.

Good, I.J. (1961-62) 'A causal calculus I-II', British Journal for the Philosophy of Science 11: 305-18, 12: 43-51.

Granger, C.W.J. (1969) 'Investigating causal relations by econometric models crossspectral methods', Econometrica 37: 424-38.

Granger, C.W.J. (1980) 'Testing for causality. a personal viewpoint', Journal of Economic Dynamic and Control 2: 329-52.

Haavelmo, T. (1944) 'The probability approach in econometrics', Econometrica 12: iii-vi, $1-115$.

Hansen, L.P. and Sargent, T. (1980) 'Estimating and formulating dynamic linear rational expectations models', Journal of Economic Dynamic and Control 2: 7-46.

Hodgson, G.M. (1998) 'Emergence', in J.B. Davis, D. Wade Hands and U. Mäki (eds) The Handbook of Economic Methodology, Cheltenham: Edward Elgar, pp. 156-60.

Hoover, K.D. (1988) The New Classical Macroeconomics. A Skeptical Inquiry, New York: Basil Blackwell.

Hoover, K.D. (ed.) (1995) Macroeconometrics, Developments, Tensions, and Prospects, Boston/Dordrecht/London: Kluwer. 
Hoover, K.D. (1998) 'Causality', in J.B. Davis, D. Wade Hands and U. Mäki (eds) The Handbook of Economic Methodology, Cheltenham: Edward Elgar, pp. 4855.

Hoover, K.D. (2001) Causality in Macroeconomics, Cambridge: Cambridge University Press.

Hume, D. (1739/40) A Treatise of Human Nature, L.A. Selby-Bigge (ed.), Oxford: Clarendon Press, 1951.

Hume, D. (1748) An Enquiry Concerning Human Understanding. in T.H. Greene and T.H. Grose (eds) The Philosophical Works. vol. 4, Aalen: Scientia, 1964.

Hurwicz, L. (1962) 'On the structural form of interdependent systems', in E. Nagel, P. Suppes and A. Tarski (eds), Logic, Methodology, and the Philosophy of Science, Stanford, CA: Stanford University Press.

Keynes, J.M. (1939) 'Professor Tinbergern's method', Economic Journal XLIX: 558-68.

King, R.G., Plosser, C.I., Stock, J.H. and Watson, M.W. (1991) 'Stochastic trends and economic fluctuations', American Economic Review 81: 819-40.

Kirman, A.P. (1992) 'Whom or what does the representative individual represent?', Journal of Economic Perspectives 6: 117-36.

Lane, D.A. (1993) 'Artificial worlds and economics, part I', Journal of Evolutionary Economics 3: 89-107.

Lawson, T. (1989) 'Realism and instrumentalism in the development of econometrics', Oxford Economic Papers 41: 236-58.

Leamer, E. (1985) 'Vector autoregressions for causal inference?', in K. Brunner and A.H. Meltzer (eds) Understanding Monetary Regime. Carnegie-Rochester Conference Series on Public Policy, 22, pp. 255-304.

Lucas, R. (1976) 'Econometric policy evaluation: a critique', in K. Brunner and A.H. Meltzer (eds) The Phillips Curve and Labor Markets, Carnegie-Rochester Conference Series on Public Policy, Vol. 1, Spring, Amsterdam: North Holland, pp. $161-8$.

Lucas, R. (1987) Models of Business Cycles, Oxford: Blackwell.

Lucas, R. and Sargent, T. (1979) 'After Keynesian macroeconomics', reprinted in R. Lucas and T. Sargent (eds) Rational Expectations and Econometric Practice, 1981, London: Allen \& Unwin, pp. 295-320.

Mäki, U. (1998) 'Instrumentalism', in J.B. Davis, D. Wade Hands and U. Mäki (eds) The Handbook of Economic Methodology, Cheltenham: Edward Elgar, pp. 253-6.

Martel, R.J. (1996) 'Heterogeneity, aggregation, and a meaningful macroeconomics', in D. Colander (ed.) Beyond Microfoundations. Post Walrasian Macroeconomics, Cambridge: Cambridge University Press.

Mitchell, S. (2003) Biological Complexity and Integrative Pluralism, Cambridge: Cambridge University Press.

Moneta, A. (2003) 'Graphical models for structural vector autoregressions', LEM Working Paper, Sant'Anna School of Advanced Studies, Pisa.

Moneta, A. (2004) 'Graphical causal models and VAR-based macroeconometrics', unpublished PhD Dissertation, Laboratory of Economics and Management, Sant'Anna School of Advanced Studies, Pisa.

Pearl, J. (2000) Causality: Models, Reasoning and Inference, Cambridge: Cambridge University Press.

Reichenbach, H. (1956) The Direction of Time, Berkeley, CA: University of California Press.

Silberstein, M. (2002) 'Reduction, emergence and explanation', in P. Machamer and M. Silberstein (eds) The Blackwell Guide to the Philosophy of Science, Malden, MA: Blackwell, pp. 80-107. 
Simon, H. (1953) 'Causal ordering and identifiability', in W.C. Hood and

T.C. Koopmans (eds) Studies in Econometric Methods, New York: Wiley, pp. 49-74.

Sims, C.A. (1980) 'Macroeconomics and reality', Econometrica 48: 1-47.

Sims, C.A. (1982) 'Policy analysis with econometric models', Brookings Papers on Economic Activity 13: 107-52.

Sims, C.A. (1986) 'Are forecasting models usable for policy analysis?', Minneapolis Federal Reserve Bank Quarterly Review winter: 2-16.

Spirtes, P., Glymour, C. and Scheines, R. (2000) Causation, Prediction, and Search, Cambridge MA: The MIT Press.

Spohn, W. (1984) 'Probabilistic causality: from Hume via Suppes to Granger', in M.C. Galavotti and G. Gambetta (eds) Causalità e modelli probabilistici, Bologna: CLUEB.

Stock, J.H. and Watson, M.W. (2001) 'Vector autoregressions', Journal of Economic Perspectives 15: 101-15.

Strawson, G. (1989) The Secret Connexion, Oxford: Oxford University Press.

Suppes, P. (1970) A Probabilistic Theory of Causality, Amsterdam: North-Holland.

Swanson, N.R. and Granger, C.W.J. (1997) 'Impulse response function based on a causal approach to residual orthogonalization in vector autoregressions', Journal of the American Statistical Association 92: 357-67.

Tooley, M. (1993) 'Causation: reductionism versus realism', in E. Sosa and M. Tooley (eds) Causation, Oxford: Oxford University Press, pp. 172-92.

Uhlig, H. (1999) 'What are the effects of monetary policy on output? Results from an agnostic identification procedure', Journal of Monetary Economics 35: 463-98. 
Copyright of Journal of Economic Methodology is the property of Routledge, Ltd.. The copyright in an individual article may be maintained by the author in certain cases. Content may not be copied or emailed to multiple sites or posted to a listserv without the copyright holder's express written permission. However, users may print, download, or email articles for individual use. 